\title{
Ethics, space, and somatic sensibilities: comparing relationships between scientific researchers and their human and animal experimental subjects
}

\author{
Beth Greenhough \\ School of Geography, Queen Mary University of London, Mile End Road, London E1 4NS, \\ England; e-mail: b.j.greenhough@qmul.ac.uk
}

\section{Emma Roe}

School of Geography, University of Southampton, University Road, Southampton SO17 1BJ, England; e-mail: E.J.Roe@soton.ac.uk

Received 21 December 2009; in revised form 3 June 2010

\begin{abstract}
Drawing on geographies of affect and nature-society relations, we propose a radical rethinking of how scientists, social scientists, and regulatory agencies conceptualise human and animal participants in scientific research. The scientific rationale for using animal bodies to simulate what could be done in human bodies emphasises shared somatic capacities that generate comparable responses to clinical interventions. At the same time, regulatory guidelines and care practices stress the differences between human and animal subjects. In this paper we consider the implications of this differentiation between human and animal bodies in ethical and welfare protocols and practices. We show how the bioethical debates around the use of human subjects tend to focus on issues of consent and language, while recent work in animal welfare reflects an increasing focus on the affectual dimensions of ethical practice. We argue that this attention to the more-than-representational dimensions of ethics and welfare might be equally important for human subjects. We assert that paying attention to these somatic sensibilities can offer insights into how experimental environments can both facilitate and restrict the development of more care-full and response-able relations between researchers and their experimental subjects.
\end{abstract}

\section{Introduction}

Geography's ethical turn has highlighted fundamental moral questions that shape, and are shaped by, relations between people and places (Proctor and Smith, 1999). Building on this, geographers have examined how ethical issues saturate our relations with nonhuman worlds (Jones, 2000), including work on practices of production and consumption that serve to either distance or bring together actors and the object of ethical concern (Barnett et al, 2002; Whatmore, 1997). This in turn has been recognised to have implications for the ethics of conducting geographical research. Both Dyer and Demeritt (2009) and Boden et al (2009) have written critically about the risks of adopting medical-style ethical review processes and procedures in the social sciences. These processes "reduce and codify ethics into sets of highly scripted rules, procedures and behaviours" and rely on regulatory ethical bodies that are remote from the research process (Boden et al, 2009, page 734), thereby failing to address the subjective and contextual nature of many ethical decisions undertaken in social research. Here we ask whether the same critique could apply to the formal ethical review procedures used in medical research. Might not subjective and contextual decisions become a part of medical and clinical research practice? What are the implications of governing clinical experiments through review procedures largely sited elsewhere?

Here we respond to these questions by asking how insights from social science and animal welfare that emphasise the situated and contingent nature of ethical practice could inform work in medical and clinical research. We identify some intriguing synergies between work in geography, which draws on nonrepresentational theory as 
a resource for developing more affective ethical geographies (Popke, 2009), animal welfare science (Baumans, 2005; Buchanan-Smith et al, 2005), and the philosophy of science and biophilosophy (Acampora, 2006; Despret, 2004; Haraway, 2008). These synergies offer a starting point for bringing geography into conversation with the discipline of bioethics. Using these approaches, we critically engage with the ways in which ethics and welfare are conceptualised and practised within medical research, providing further evidence of how science intervenes in relations between human and animal bodies. This work therefore builds on earlier studies of the ways in which relations between nature and society and space are reconfigured through practices, such as animal conservation and trade (Whatmore, 2002), xenotransplantion (Davies, 2006), genetic-based livestock breeding programmes (Holloway, 2005); and practices of biosecurity (Braun, 2007; Hinchliffe and Bingham, 2008).

\section{Ethics, welfare, and experimental subjects}

The use of human and animal subjects to research, develop, and test new drugs and clinical interventions is fundamental to the advancement of medical research and practice, at least until viable replacements are found. Equally important are the ethical guidelines and welfare protocols that shape the conduct of such research. These guidelines and protocols mark the interface between the experimental needs of medical and scientific researchers and the socially acceptable degree of suffering the experimental subjects should endure and/or consent to for research benefits. However, there is a marked distinction between human phase regulations, which focus on issues of patient recruitment and consent, and the laboratory animal phase that focuses on the "three Rs' of reduction, refinement, and replacement.

A range of legislative measures governs UK research involving human subjects, including the Medicines for Human Use (Clinical Trials) Regulations (2004) and the European Union Clinical Trials Directive (2001). In addition, funding and professional research bodies issue their own guidelines for the conduct of clinical research, such as the Medical Research Council's clinical trials tool kit (MRC, 1998). These texts lay down the principles for the ethical recruitment of and use of human subjects for research. Within these ethical protocols and guidelines, there is a strong focus on the human ability for language and rational communication. It is the capacity of human subjects to give 'informed consent' which is seen to mark out the key distinction between the ethical treatment of human and animal subjects (MRC, 2005, page 4). Correspondingly, bioethical debate also tends to focus on the underlying principles that shape the use and recruitment of human $^{(1)}$ volunteers and associated codes and procedures, such as ethical review and informed consent. See, for example, bioethical analyses of informed consent procedures (Boulton and Parker, 2007; Dawson, 2003; Hoeyer, 2003), the use of placebo (Ehni and Wiesing, 2008); the use of inducements to recruit participants (Edwards, 2006); equipoise (Ashcroft, 1999), and balancing patient risk against the benefit to society (van Ness, 2001). Social scientists and anthropologists have also begun to question the autonomy of volunteers' decision-making processes, arguing that wider social, political, and economic conditions influence a decision to join or refuse participation in a clinical trial (Petryna, 2006; Rajan, 2007).

Conversely, for animal subjects it is their inability to speak, but an ever-increasing sensitivity to their ability to suffer, that has shaped ethical protocols and popular antivivisectionist campaigning and protest. Animal welfare guidelines and legislation still emphasise Russell and Burch's (1959) 'three Rs': reduction (of the number of animals used), refinement (of testing procedures to minimise suffering), and replacement

(1) In the work we have reviewed so far bioethics has focused on the use of human (as opposed to nonhuman animal) materials, subjects, and interests in scientific research. 
(of animal models with alternatives) (Boo et al, 2005; Fenwick and Fraser, 2005; Vorstenbosch, 2005). Increasingly, however, these are being supplemented by an emphasis on the welfare of animals within the laboratory environment, driven by the European Community's 1997 Amsterdam Treaty protocol, which desires "improved protection and respect for the welfare of sentient beings". There is an assumption that good welfare is beneficial to both the experiment and the animal and, conversely, that "unhappy mice give bad information" (O'Hanlon, 2001). In contrast to the human bioethical focus on language and informed consent, the animal welfare literature focuses on the practicalities of following ethical protocols [although see Dyer (2004) on the practice of lay participant involvement in research ethics committees]. Animal welfare practitioners (unable to use language to communicate with their research subjects) are using welfare assessments to attend to bodily practices and sensations that are a somatic response to the day-to-day experience of being an experimental subject.

This emphasis on more-than-verbal forms of communication is an interest shared by both animal welfare scientists and those working with animals and a number of contemporary geographers and social theorists. Recent research in geography and social theory has been interested in how bodies shape our relations with the world (Butler and Parr, 1999; Grosz, 1995; Longhurst, 1997; Nast and Pile, 1998) and other sentient species within it (Acampora, 2006; Despret, 2004; Lorimer, 2006; Lorimer, 2007). Drawing on nonrepresentational theory (Dewsbury, 2000; 2003; Thrift, 2008), geographers have explored how emotions and feelings shape spaces and encounters in ways that cannot easily be captured by the tools of language and text (Anderson, 2006; Harrison, 2007). McCormack's (2003) empirical account of a dance movement therapy class shows how ethics and emotion may be expressed not through language but through affectual registers, including touch, gesturing hands, and bodily movement [see also Paterson (2005) on the use of therapeutic touch in Reiki massage]. Lea's (2009) analysis of the teaching of Thai yoga massage leads her to stress the corporeal as well as cultural contexts of learning an embodied skill. This work is characterised by an emphasis on bodies, the affectual or nonrepresentational kinds of relations they perform, and of particular relevance to our concerns here, how those relations inform emotional responses and practices which generate particular spaces of care. Health geographers, too, have argued that the body plays a key role in shaping our relations with biomedical science (Hall, 2000; Parr, 2002). Here we suggest it is not just human bodies which should be taken into account. Experimental practices in both human and animal research are changing relations between human and animal bodies (Birke et al, 2007; Despret, 2004; Franklin, 2007; Haraway, 2008). Animal welfare-with its shared interest in more-than-verbal, or nonrepresentational, forms of engagement between bodies-might therefore offer some interesting insights for geographers concerned with how relations between researchers and their human subjects may also be shaped by affectual and embodied communications and registers.

Our analysis draws on preliminary work exploring how a situated, affectual, and embodied ethics plays out in two related research arenas: clinical trials and animal experimentation. Sources include interviews and informal discussions with experts in bioethics, clinical trials and animal welfare, formal legislative and regulatory documents on the protocols and procedures for clinical trials and animal testing, and a review of the related literature in the fields of bioethics and animal welfare. In the following section, we begin by drawing on research from the fields of nursing and medical sociology, which highlights some of the implications of focusing on an ethics grounded in language and formal procedures and paying less attention to the everyday processes of care. We seek to contrast the formal linguistic codes and practices of 
research ethics for working with human and animal subjects with a more relational (Whatmore, 1997) 'situated' ethics (Greenhough, 2007) that emerges from affectual, embodied understandings of human and nonhuman relations. We are working towards an ethics that is "less about dour denouncements of injustice or sober analyses of normative principles and more about enhancing, and celebrating, our immersion in Being" (Popke, 2009, page 81). We then compare the care practices of clinical trial nurses with recent work in animal welfare. We suggest that the current emphasis on the welfare of animal subjects is highlighting somatically sensitive relationships between researchers and researched, redefining what might be seen as response-able research practice. The final sections argue that current understandings of ethical practice in research with both humans and animals may be reconfigured and enhanced though an emphasis on somatic sensibilities and the spaces of welfare and day-to-day care they inscribe. We also note some of the limitations and challenges of this approach.

\section{Situating ethics in clinical trials}

The ethics of clinical trials involving human subjects have long been a focus of debate and research within bioethics. Since the Nuremburg trials (1945-46) and the first Declaration of Helsinki (1964), the process of recruiting volunteers for medical and clinical research has become increasingly regulated (Dyer and Demeritt, 2009). In the UK, trial participation procedures are enacted through a network of local and multicentre research ethics committees. These committees establish whether the potential benefits of a medical trial are worth the risk to the human subjects recruited and whether the correct procedures and protocols are in place to ensure the ethical recruitment of volunteers and volunteers' welfare during the experimental process [for an overview see Dyer (2004)]. While we do not contest the importance of both ethical review committees and procedures, and their bioethical critiques, here we suggest that these are not the only situations within the experimental process where ethics takes place. In the following paragraphs we draw on evidence from the nursing literature to suggest that ethical dilemmas and responses also permeate the day-to-day practices of running a clinical trial. Furthermore, we suggest that the kind of ethical dilemmas and responses that arise during the process of experimenting with human subjects are qualitatively different to the more abstract technical and moral questions currently addressed by ethics committees and informed consent forms.

During the day-to-day running of a clinical trial a key role is played by Clinical Research Nurses (CRNs). While there is considerable local variation in the range of roles and tasks performed by a CRN, the UK Royal College of Nursing's (RCN) competency framework (a tool designed to assist nurses in their continuing professional development) identifies four key aspects of the CRN's role:

- Knowledge and understanding of the evolution of clinical research (including regulatory and governance frameworks).

- The application of knowledge and skills in the clinical research environment (including knowledge of research design, financial management, an understanding of the research process, personnel management, data collection, the completion of study documentation, and data storage).

- The ability to work within, and adhere to, the requirements of research ethics, research governance, and legislation (including seeking ethical approval and ensuring the confidentiality of participants).

- Understanding the principles and practice of obtaining valid informed consent (RCN, 2008). 
These competencies suggest that the key role played by the CRN is one of manager and data collector, while their responsibility towards patients is subsumed under the management of patient-public interaction as part of research governance. Patientpublic interaction includes such tasks as preparing patient information leaflets and answering any questions the patient and members of the public may have about the study. The list of competencies also stresses a CRN's role in facilitating ethical research by obtaining valid informed consent, reflecting how nurses are increasingly positioned as a kind of bioethical gatekeeper responsible for implementing ethical procedures set out by research protocols and approved by research ethics committees. For example, the RCN (2006) offers detailed guidance on how to obtain informed consent - through the discussion (where the nurse conveys key information about the study seen as necessary to 'inform' consent), reinforcing the discussion with a written document (patient information leaflet), and the signing of the consent form.

This emphasis on informed consent is reflected in Andersen's (2008) review of twenty-nine (post-1992) articles on gene therapy trials in the nursing literature. She found that where ethics and ethical training for nurses is discussed the emphasis is on the nurse's ability to implement informed consent procedures, which oblige them to adequately 'inform' patients about the techniques involved in the study. Relatively few authors "emphasise the role of providing direct care during or following gene therapy" (Andersen, 2008, pages 209-210). This emphasis on formal informed consent procedures may seem in line with ethical research, yet Fisher (2006, page 686) also stresses that from a pharmaceutical industry perspective it is increasingly recognised that "informed consent can encourage patient-subject compliance", recruitment, and retention. At the same time the kind of ethics represented by the informed consent processes - which emphasises the need for patients to choose of their own free will to participate in research - is only one version of ethics. As we will go on to argue, it says little about the other roles played out by nurses in ensuring the care and welfare of research participants. The emphasis on sensing and observing bodily responses, which is made explicit in animal welfare assessments, remains largely hidden in accounts and descriptions of the nurse's role in clinical trials. In this section we begin by drawing on empirical research from the US ${ }^{(2)}$ that suggests that the role set out for nurses by the CRN competencies might conflict with nurses' own understanding of their role as carers. We then argue that there are other aspects of nursing which need to be taken into account when establishing what counts as ethical research practice.

Studies in the US have found that in practice many nurses have found it difficult to adapt to the kind of 'research manager' role described above. Mueller (1997) describes how, in her study of a clinical trial for AIDS medication in the US, nurses found it difficult working with patients without health insurance. These patients could not afford to supplement the trial's treatment regime with private medical care and treatments that could improve their care or relieve suffering. The nurses argued that the trial should offer additional medical care to these patients as a value-added benefit of participation. The physician investigators leading the trial disagreed, arguing that these treatments were not part of the trial's budget and even suggested patients without insurance should be excluded. Mueller (1997, page 67) suggests that while physician investigators "seek to draw the boundaries around clinical trial practice narrowly" nurses "view clinical trials as an extension of medical care".

(2) We have been unable, yet, to find any similar studies of clinical trial nursing practices in the UK which focus on balancing the nurses' vision of their role as carer with their role as manager and data collector. We are in the process of planning empirical research to address this gap, but in the interim the US case studies offer a useful proxy. Anecdotal evidence suggests that the situations and experiences they describe are also shared by many UK CRNs. 
Mueller also notes how nurse coordinators ${ }^{(3)}$ found they built up a connection, in particular, with these patients. The following quote is taken from one of her interviews:

"Here it's week after week, month after month, year after year ... . You watch them suffer .... You watch their lovers die of AIDS in their arms. You watch their friends reject them. You watch them in pain. You watch them [become] physically disfigured. These are huge, huge issues as far as how you can just do your job" (page 68, emphasis added).

The nurse's language reflects how her role as a research manager and data collector seems to be in conflict with the empathetic relationship she has formed with her patient. Fisher (2006, page 684) further notes that this kind of conflict is intensified by the length of many trials and because, "unlike standard medical care, coordinators are not only allowed but encouraged to spend a significant amount of time with patientsubjects". The example reflects wider tensions often noted by nurses involved in clinical trials between their role as data managers and collectors, as a kind of scientific observer, and their need to care for their patients (Andersen, 2008; Fisher 2006; Mueller 1997). ${ }^{(4)}$ This distinction is easily recognisable in the clinical trial context as "the inherent conflict between doing what is best for patients versus doing what is best for scientific integrity" (Andersen, 2008, page 210). This conflict is echoed in the nurse's description, whereby the process of scientific observation-of watchingbecomes infused with the frustrated need to care for the patient, to try and relieve their suffering. Gradually this need to care becomes an impediment to 'just doing your job' in research practice. This conflict is arguably exacerbated by the increasing trends towards the privatisation of clinical trials, where nurse coordinators have difficulty reconciling their training as patient carers with the pharmaceutical company's central goal of drug development (Fisher, 2006). In practice CRNs and patients alike can struggle to separate out the research trial from patient care. Fisher cites one of the nurse coordinators she interviewed who suggested that:

"It's just getting that thing in your head that it's not a patient-doctor or nurse relationship. It's a participant-research [relationship] and making that clear .... That, 'Yes, you're important as an individual, but it isn't a doctor-patient relationship' ... [There was a] participant we had that was doing this [study] for psoriasis. It was unfortunate that out of the four people that have [been enrolled in the study], he was the one [whose condition] was the worst and had been getting worsewhich was why he came in. Well, we were almost sure he got the placebo. He got no effect .... Even though he'd read the informed consent and we'd explained it to him, he didn't understand it well: 'How would they pick me to not get the drug when I'm so bad?' ... . He still seemed a little dumbfounded by it because you're in a medical setting, sort of .... We're doing medical tests and they're still expecting

(3) Nurse coordinators have a similar role to $\mathrm{CRNs}$ in the UK and are responsible for the day-today running of clinical trials, ensuring the implementation of trial protocols, and undertaking data collection and patient care.

(4) There are three key (prelicence) phases of human trials for new medical drugs and treatments. Phase 1 human trials establish whether the drug has any negative effects, how quickly it enters and leaves the body and what effects it has on target cells or proteins. These involve a very small number of healthy subjects $(10-20)$ and are usually carried out in dedicated facilities. Phase 2 human trials are used to establish how safe and effective the drug is for the intended use and involve patients who have the condition the drug is being developed to treat. These are usually controlled, meaning that some patients will receive the trial drug, others a placebo or existing treatment. Phase 3 human trials (also controlled) are much more extensive evaluations of the longterm safety and effectiveness of the drug on a wider selection of several thousand patients with the target condition (ClinicalTrials.gov, 2007). It should be noted that the trials described here are phase 1 and 2, although similar dilemmas arguably arise for doctors when they are asked to act as recruiters for phase 3 clinical trials. 
medical treatment appropriate for their [conditions], even though you've told them otherwise" (Coordinator B, cited in Fisher, 2006, page 684).

It is at this moment when the current ethical provision might be found wanting. Recent work in nursing research has begun to suggest that there may be more to ethics in nursing practice than is captured in current bioethical debates about procedures and informed consent. Given the limitations of informed consent procedures in managing either patient's expectations of care or CRNs' impulse to offer such care, the kind of ethical response nurses may make towards patients in their care is unlikely to be captured in the formal process of obtaining informed consent. This conclusion is supported by recent research in nursing which is turning to consider the value of notions of embodiment (Lawler, 1991) for understanding nursing practice. For example, Gobbi (2005, page 117) describes nursing as "an embodied, bricoleur practice where practitioners draw on the 'shards and fragments' of the situation-at-hand to resolve the need of the individual patient for whom they care." Rudge (2009) in a study of a burns unit, talks about the need to pay attention to micro-ethics, grounded in the day-to-day interactions of patients and nurses and their embodied experiences, as well as looking at larger bioethical debates about consent. This emphasis on embodiment draws out a distinction between the more objective-making managerial competencies determined by the CRN job description and the more embodied approach to care that characterises nursing practice. This emphasis on the role of embodied sensibilities in shaping the relationships between nurses and their patients finds echoes in recent work within health geography describing how landscapes of care are inscribed by the relationships between able and less able/sick human bodies (Parr, 2002). Significantly this work draws attention to how care "is performed in complex conditions of materiality, embodiment, fields of competing knowledges and social relationships" (Dyck et al, 2005, page 181). However, the question of how to recognise and incorporate such situated and embodied understandings of ethics and care in the guidelines for experimental research practice remains, and we recognise it as an area where bioethics has yet to develop. In the following section, we offer one route to this goal drawing on recent work in animal welfare science.

\section{Practising animal welfare: making space for somatic sensibility}

Shifting species, recent work on animal ethics has moved from focusing on the rights and wrongs of vivisection towards a more detailed consideration of the welfare of specific kinds of experimental subjects (Birke et al, 2007). The principles of reduce, refine, and replace (Russell and Burch, 1959) still play a key role in the ethical evaluation of proposed animal experiments. Now, though, greater focus is being placed on the welfare of animals within the laboratory environment, seeking to directly address the needs of the sentient being. A welfarist position extends the principle of refinement by paying attention to housing and husbandry, providing environments that allow animals to express 'natural' behaviour (Baumans, 2005; Buchanan-Smith et al, 2005). In some places this has been developed into the observation of animal behaviour and demeanour to signal their emotional state (Wemelsfelder, 2007).

One animal welfare expert we spoke to (interview, August 2007) described how this might play out in practice, identifying an opportunity to refine an experimental process to reduce suffering:

"So, for example if a researcher wanted to put 200 micro litres (1) into a mouse's ear ... introdermally, well 2001 is a lot of fluid ... it doesn't seem much to us ... but for a mouse? ... And into its ear where there is hardly any skin thickness at all." 
Our informant also noted that his role as an animal welfare expert (a veterinary scientist), who recognises the animal as a sentient living being, is often in conflict with scientific researchers who see the body as a series of biological and chemical systems. "I think there is a resistance from scientists to take up the three Rs recommendations because they see it as not necessary, extraneous ...", explained the informant. There is a conflict between those who see the experiment from the perspective of animal welfare and those who focus on the research aims and objectives. ${ }^{(5)}$ This conflict arises from different ways of knowing the experimental subject informed by different knowledge-practices of a laboratory scientist carrying out an animal experiment and those of a veterinary expert in animal welfare responsible for ensuring animal welfare in the laboratory. For the scientific researcher, the animal is effectively a 'black box' (Latour, 1993). For the veterinary expert in animal welfare, and often also for those tasked with the day-to-day care of the animals, the animal subject is a being to be cared for and with which there is communication. Though it is seemingly self-evident that a conflict of interests will arrive, close attention to how different knowledge-practices generate different expertises for the experimental subject raises awareness about where they do or do not complement and where the potential lies to coalesce. This issue of how to reconcile the two roles is equally significant for clinical trial nurses, who effectively serve as both carers and scientific observers. In both cases we wish to ask what would need to enter the suite of knowledge-practices of the laboratory scientist (or the CRN job description) for the communicating animal (or the sense-able patient) to become available to him or her? In seeking to address this question we turn now to consider in more detail the interspecies communication performed by laboratory vets and animal caretakers.

So how is this interspecies communication practised? Our animal welfare expert described how he began with a model of a human subject, deciding how he might feel in the place of the animal subject, and then adjusted this representation through what he knew about the animal's physiology, sentience, and cognitive development:

"How do you recognise when an animal is in pain or not? ... I use anthropomorphism quite unashamedly all the time. I always put myself in the animal's position and from that work out what I would feel if I was an animal ... and that became the basis for most of the clinical assessments of suffering" (interview with animal welfare expert, August 2007).

The informant describes what he does as anthropomorphism, which initially seems like an unpromising space in which to start. After all one of the key critiques to emerge from a posthumanist interrogation of animal ethics is a rejection of the moral anthropomorphological extension of human ethics (and representation) to animal subjects. This is what Wolfe (2003, page xii; see also Acampora, 2006) calls "one of the central ironies of animal rights philosophy". Likewise a leading edge of veterinary surgeons argue that "the human tendency to anthropomorphise means we miss out on animals' real feelings and needs, with the result that we often provide them with inappropriate housing and medical care" (Coghlan, 2006, page 6). For this reason, some animal welfare scientists prefer to name their practice as critical anthropomorphism. Critical anthropomorphists draw on a combination of their "intuitions about what is best for an animal, based on a knowledge of ourselves and other people", but "tempered by

(5) Unlike the dual role played by CRNs in nursing practice, within animal research there is usually a clearer division of labour between the laboratory vet and animal caretakers tasked with caring for and ensuring the welfare of the research subjects and the scientific researchers tasked with carrying out experimental protocols and collecting data. 
objective knowledge of the particular species" (or individual animal's) life history, behaviour, and physiology (Morton et al, 1990, page 1). ${ }^{(6)}$

The critical anthropomorphist approach picks up on many aspects of animal care and welfare (and arguably human care and welfare) which escape the more formal codes and criteria that regulate laboratory practice. We suggest that these skills employ what Acampora (2006, page 130) calls "somatic sensibility", a phenomenologically derived compassionate concern for the other as a "proper object or 'patient' of ethical consideration". For Acampora these somatic sensibilities generate relations of "symphysis", (7) a term he uses to convey "the sense of sharing with somebody else a somaesthetic nexus experienced through a direct or systematic (inter)relationship", rather than "the more airy, psychic notion of sympathy" (2006, page 76). The symphysis relationship is "densely physically orientated" (page 76), available to those who share "physical vulnerability - susceptibility to injury and illness, just by virtue of being sentient entities of animate flesh" (page 130). In other words, for Acampora, the same shared vulnerabilities that make animals appropriate models for predicting the effects of drug-compounds on human subjects might also be the basis for developing more ethical experimental relations.

It is these somatic sensibilities that enable somatic gestures - such as bodily comportments and facial expressions - to be apprehended through shared experiences of having a body. While not all formally taught or required, ${ }^{(8)}$ these skills and capacities play a key role in allowing the vet or animal caretaker to sense an animal's welfare needs. Our laboratory animal welfare expert describes how those responsible for the day-to-day care of animals: "have incredible expertise at picking up when a mouse is not well. They can tell when something is going wrong, when the animal is going to die, when it's not right for some reason" (interview, August 2007).

Animal caretakers, not unlike good stockpersons (Morton et al, 1990) serve as transistors in the circuits of somatic sensibility, becoming experts in interbodily communications, developing a repertoire of skills that supplement a generalised somatic awareness with species-specific sensitivities developed through time spent with chickens, or monkeys or mice, for example. This embodied expertise in somatic sensibilities is what enables a 'good' animal caretaker to know when something is wrong with an animal in their care, ${ }^{(9)}$ and perhaps equally enables a nurse to sense (unvoiced) unease

(6) The critical anthropomorphism term that developed in the animal welfare science literature two decades ago is never referenced in contemporary animal studies literature in the humanities and social sciences (eg Wolfe, Calarco, Haraway). Animal studies literature has addressed it in less practical terms, a reason why we favour the animal science definition here.

(7) In ancient Greek it means a 'state of growing together' (Seamon in Acampora, 2006, page 159).

(8) The Farm Animal Welfare Council (FAWC, 2007, page 7) identifies "knowledge of animal husbandry", "skills in animal husbandry" "Personal qualities", "affinity and empathy with animals, dedication and patience" as essential for stockmanship. Laboratory animal welfare governing bodies to date have not identified the essentials for laboratory animal technicians, although they may broadly be considered similar to those for stockmanship.

(9) An example of how this repertoire of skills might work in a different context is found in the work of the animal scientist Temple Grandin, who offers a potential insight into how successful a nonempathic, but certainly shared somatic sensibility with animals might be used to intervene in and change the relations between humans, animals, and environments. As an autistic person, Grandin further represents a figure who stands outside the normative Cartesian ethical subject and is well placed to suggest alternative ways of becoming sensitive to the responses of nonhuman others. Grandin (2006, page 201) argues that animals and autistic persons share somatic similarities, including an ability to "think without language" by "associating sensory-base memories such as smells, sounds or visual images into categories", feats of great memory, thinking in details, and a sensitivity to tone. Her work involves drawing on her shared somatic sensibilities with animals in redesigning abattoir environments to lessen animal stress. A third of all cattle and hogs in the US are now handled in slaughterhouses following her designs. 
or discomfort in their patients. Critical anthropomorphism therefore offers a model for recognising more explicitly the role of somatic sensibilities in providing good care. This work provides a starting point for thinking through how animals (and humans) might relate and respond differently to the experimental environment, and in turn how we might think differently about our responsibilities (defined as ethical or otherwise) towards them.

\section{Becoming articulate in experimental space}

So far then, we might argue that clinical trial nurses, laboratory vets, and animal caretakers have some things in common, an ability to sense and respond to nonverbal as well as verbal signs of distress, discomfort, and suffering in the humans and animals in their care. However, clinical trial nurses are seemingly constrained in their capacities to respond to these signs by experimental protocols (which emphasise scientific objectivity and informed consent), and in the US example by clinical trial budgets. Even when caring does take place-as it undoubtedly does - it seemingly slips under the radar of formal accounts and ethical procedures, as reflected in Andersen's analysis of papers on gene therapy trials (2008). Fisher (2006) describes how for one nurse the conflict became too much:

"In one remarkable case, a coordinator who had 14 years of experience convinced the physician for whom she was working to stop accepting particular studies. In her telling of this story, she had done multiple studies for several different pharmaceutical companies on cox-2 inhibitors (eg Vioxx, Celebrex, Bextra) and saw the negative effects that this type of drug was having on patient-subjects: I finally got to the point where I said, 'No, I don't want to do these studies'. And so I had to talk to Dr. X and say, 'You know these meds? We're supposed to be here helping mankind and these medicines aren't. They're making them worse and [causing] a lot of pain. That's not what we're here for, so I don't want to do these studies. If you want to do these studies, that's fine, but you'll need to find somebody else to do it for you. Because I can't legitimately give people these medications" (Coordinator D, cited in Fisher, 2006, page 685).

Here it is the nurse's sense of patients' bodily discomfort and distress, rather than the patients' verbal and written decisions to participate or not, which are informing her (ethical) decision to no longer facilitate the study. Indications are that nurses in their day-to-day practice are developing a range of skills that make them sensitive to precisely the kinds of nonverbal signals (such as sensing pain) which form part of the competencies of their counterparts in animal welfare. For example, Rudge (2009) describes how nurses in a burn unit often have to witness injuries, pain, and suffering which effectively render them (the nurses) inarticulate. Their response relied not on words but on practices of care, assessing and dressing wounds and later on teaching patients to facilitate their own care. The contexts of Fisher's and Rudge's examples are different (clinical trial versus aftercare in a severe burns unit) and so are the responses, a refusal to continue with a trial (Fisher) and the adoption of more careful, skilful practices of treatment (Rudge). However, in both cases the focus is less on abstract bioethical principles and formal consent procedures and more on the relationships and response-abilities established between nurses and patients informed by the experience of giving and receiving care and treatment. This emphasis on what Rudge calls a micro-ethic of care, embodied in the skilled and careful practice of procedures, offers a striking parallel with the earlier description of injecting a mouse's ear. Within laboratory animal welfare, while practices of care are still constrained by and subsumed to following experimental protocols, these kinds of somatic sensibilities are taking on a much more prominent role in developing recommendations and 
procedures for ensuring good animal welfare and also, importantly, good experimental practice. So, what can the emerging welfarist position offer our understanding of a more-than-representational (Lorimer, 2005) ethics?

In the preceding sections we have argued that in order to rethink the ethics of experimental research with sentient subjects we should not focus on what differentiates human and animal subjects - a focus on verbal consent. Instead, we might look towards what human and animal subjects have in common. Firstly, a capacity to respond, in nonverbal ways, to both the experimental process and the wider laboratory environment. Secondly, a capability to be cared for that spans across and between species (although, as noted below, perhaps more readily between some species than others). We argue that, while there are scientific and ethological reasons for some of the differences in how human and animal subjects are treated in ethical protocols, the current emphasis on what makes humans distinctive from other species (the ability to speak) fails to engage with similarities in their care needs - or with the different kinds of consent and cooperation care practices foster during the experimental process. In this section we suggest how experimental research frameworks (working with either human and/or nonhuman subjects) could be reconfigured and enhanced through an emphasis on care-relating, consent, and cooperation articulated through bodily communications [as seen in the most progressive examples of animal welfare protocols which incorporate the observation of animal behaviour and demeanour to signal their emotional state (Wemelsfelder, 2007)]. Following Whatmore (1997), we argue for a rejection of the rational, autonomous human subject as the key figure of ethical concern and for its replacement with a 'relational ethics' based not on universal or normative codes but on a sense of shared culpability and connection. This move requires new tools and competencies.

Until recently we would argue that the majority of ethical protocols, such as the more formal ethical review processes and informed consent forms, have relied on the practices of representation. Either individual research subjects represent themselves through giving their 'informed consent' or, more usually, experts capable of articulating the 'interests' of research subjects do so in the appropriate technical and procedural language. However, if we are to pay attention to how ethics is done in practice with sentient beings, then we also need to look beyond the dedicated spaces of the ethics committee (and the responsibilities set out in the CRN competencies) to understand how ethical practices and notions of care and responsibility infuse everyday experimental practice. So far this is a familiar move to many of those who have critiqued the informed consent procedure, drawing attention to how informed consent is rarely the free and autonomous decision it was designed to be (Boulton and Parker, 2007; Dawson, 2003; Greenhough, 2007; Hoeyer, 2003). Here we wish to go further in emphasising how consent - or at least cooperation with the experimental process - might be nonverbal (see also Hoeyer, 2003) and dependent on the creation of environments where subjects remain articulate in the broadest sense. This in turn places new kinds of obligations on the experimenter to develop their competency in sensing the ways in which they and their sentient subjects react to the experimental environment-what Haraway (2008) might term response-abilities.

For Haraway (2008) it is the capacity to respond (as opposed to the capacity to express a reasoned argument through language), which is the starting point for an ethical_or at least mutually responsible_engagement with an experimental subject. For Haraway ethical practice involves not just getting informed or expert consent but reading and responding to nonverbal cues and signals and "cultivating [a] sensitivity to [the] context" (Thrift, 2003, page 94) in which the research subject is enacted. This then asks the experimenter to adopt a disposition within experimental space that is able to 
sense and respond to the emotional and somatic sensibilities of those with whom they are working. The political theorist Jane Bennett (2001, page 3) describes this as a kind of comportment, an ethical generosity and sensitivity towards (an)other:

"Codes and criteria are an indispensable part of ethics, and they surely will not work without a sense of obligation or subscription. But these last things are still not sufficient to the enactment of ethical aspirations, which requires bodily movements in space, mobilizations of heat and energy, a series of choreographed gestures, an instinctive assemblage of affective propulsions." (10)

This position echoes recent work in geography that emphasises the relationship between motion and emotion (McCormack, 2003; Paterson, 2005). For example, McCormack's account which fleshes out an empirical practice for developing a somatic sensibility, for exchanging and responding to feelings and actions through the bodies of sentient others. This work, along with other work that details intrabodily communications (Katz, 2000; Rudge, 2009), could indicate how to progress towards developing an empirical practice for experimenters and ethical practitioners in both medical research and geography.

Despret (2004) makes a similar argument to McCormack, but in her case she explores the relations between animals and humans-or what she terms anthropozoo-genetic practice-emphasising how both researcher and researched are transformed by a shared experimental encounter. Despret uses the example of students working with laboratory rats and describes how the enthusiasm and care the students expressed when working with their rats helped encourage the rats to cooperate with the experiment. Furthermore, she suggests that:

"These emotional relations, made of expectations, faith, belief, trust, which link each rat to each student, disclose the very essence of the practice: this is a practice of domestication. As long as this practice proposes new ways to behave, new identities, it transforms both the scientist and the rat .... The rat proposes to the student while the student proposes to the rat a new manner of becoming together, which provides new identities: rats giving to students the chance of 'being a good experimenter', students giving to their rats a chance to add new meanings to 'being with a human', a chance to disclose new forms of 'being together'" (Despret, 2004, page 122).

Despret's example echoes the accounts of animal welfare practice above in suggesting that the quality of care received by the experimental subject can shape the quality and validity of the experiment. Yet she also develops this through her insistence that the two-way relationship between student and rat, researcher and researched, is not a given. It is conditional upon the spaces and environment established by the protocols and apparatus of the experiment. The maze experiment conducted by humans and rats above allowed the rats a choice: they could either join in with the maze experiment or resist, refuse to participate. This possibility of refusal is important, as by refusing, or at least having the opportunity to refuse participation, the rats becomein Despret's words - articulate. They can refuse to answer the questions addressed to them or even, through their resistance and behaviour, suggest new, more interesting questions. While conventional wisdom claims that the difference between humans and animals is a capacity to give 'informed consent' (MRC, 2005, page 4), here the capacity to consent, or at least to refuse participation, is something extended to nonhuman subjects.

(10) The challenge is to train experimenters to be open to the emotional sensibilities of their experimental subjects, an impulse that would run counter to the way in which objectivity is stressed in current scientific research training. 
Despret contrasts her rat experiment with another kind of experiment, in which an environment is designed for exploring the effects of depression in a Rhesus monkey. ${ }^{(11)}$ Here the environment and experiment are designed to make monkey both docile ${ }^{(12)}$ and depressed. However, by designing the experiment in this way, Despret argues, the scientist effectively offers the monkey no chance of resisting this diagnosis: it renders the monkey inarticulate. The monkey experiment, we might suggest, thereby reflects more the nature of the experiment than the nature of the monkey - or, as O'Hanlon (2001) might suggest, unhappy monkeys also give bad data. Here we find echoes of Stengers's (1997, page 17) recognition of how the social and material construction of experimental space can render the subject of empirical investigation either articulate or dumb by enabling or suppressing respectively their capacity to respond. Not to allow our object/subjects to object or resist is to run the risk of effectively silencing the object/subject of analysis and producing results that reflect the effects of the experimental environment more than the effects of the substance, compound, or medical treatment under study.

This notion of resistance has important and interesting parallels with the process of giving consent to participate in an experiment. Just as good clinical trial practice requires volunteers to cooperate in the experiment, so do good laboratory students need the rats with whom they are working to participate cooperatively in the making of the experiment. However, there are two important distinctions between the abstract ideal of 'informed consent' and the kind of embodied cooperation described by Despret. Firstly, while informed consent is dependent on language, embodied cooperation can also be nonverbal (through, for example, relaxing enough to allow blood to be drawn) and demands instead a degree of somatic sensibility and emotional sensitivity-Despret (2004) calls it trust-between the researcher and researched.(13) Secondly, while informed consent requires a formal procedure, and usually a signature, the development of somatic sensibilities requires a particular kind of space-or context-and an experimental design that allows the research subject to articulate. For example, to be able to express nonverbal consent - a kind of bodily compliancethrough a more relaxed demeanour. At the same time it is important to remain aware that the capacity to refuse participation by not giving consent (whether verbal or nonverbal) is more limited for some species than others (humans are usually more able to refuse participation than other species) and for some more vulnerable ${ }^{(14)}$ human subjects than others. In the final sections, we will now turn to ask what this attention to more-than-representational (Lorimer, 2005) ethics might offer both scientific and social science researchers, as well as noting some of the limitations of this approach.

(11) Here Despret is referring to the primatologist Harlow's experiments separating newborn monkeys from their mothers and peers. The newborns, isolated in cages for months, developed pathological and self-destructive behaviour, despair, and very deep depression according to Harlow (Despret, 2004, note 10; see also Harlow, 1964).

(12) It is perhaps interesting to note here that one of Fisher's (2006) concerns with the informed consent process within human clinical trials is that from the perspective of trial organisers the informed consent process serves to render research participants more compliant with trial protocols and less inclined to withdraw from the trial.

(13) This is not to say talk is unimportant for relations between nurses and their human subjects. Indeed it can play a key role in building relations of trust (Fisher, 2006), but this kind of interpersonal communication is distinct from the abstract notion of a rational actor making an autonomous decision to consent.

(14) Here vulnerable human subjects may include both those subjects judged not capable of giving informed consent (eg those deemed mentally incapacitated), and those subjects whose economic circumstances may force them to make choices (for financial or other rewards) they would rather not have to (Rajan, 2007). 


\section{Problems and prospects: towards a cross-species ethics for experimental subjects}

Shifting from a focus on the capacity to consent to the recognition of an affective capacity to respond, and from knowing at a distance to caring, marks a starting point for considering what different kinds of experimental subjects might have in common. Despite the persistence of techniques that differentiate humans and animals, there are a number of experiences and issues, shared by all kinds of experimental subjects, where the human-animal distinction appears less profound. After all, it is their bodily similarities, or shared responses, which form the primary justification for using animal models in research on human medicines in the first place. These include the welfare needs of sentient beings; consensual experiences of being an embodied experimental subject; and physiological similarities between human and human, human and animal, animal and animal, and researcher and researched. As Anderson and Harrison (2006, page 334) suggest, paying attention to the affective and emotional dimensions of a relationship allows other understandings of subjectivity to emerge:

"[It] should lead to questions over the emergence of subjectivities from more or less unwilled affectual and emotional assemblages and the consequences of such questions for reflexivity, responsibility, intentionality, autonomy and identity."

More than 200 years ago it was recognised that in practice the seemingly neat distinction between a rational, informed, autonomous human subject who can give consent to an experimental procedure and a 'dumb animal' that cannot/can be hard to sustain. As Bentham noted, "The question is not, Can they reason? Nor, Can they talk? But, Can they suffer?" (1789, page 283). From this perspective the notion of nonverbal consent - or cooperation-opens up an interesting possibility. Perhaps the key question is not 'Can they give informed consent?', but do they have an opportunity to resist or contest their enrolment and treatment (being objectified) in the experimental process. Such a question is immediately sensitive to the differences between the research conditions of human and animal subjects: humans can ultimately refuse to participate while animals may be forced to participate, however much they try and resist. At the same time, though, it also emphasises the blurriness of this boundary, in the form of human subjects who, due to economic and social circumstances, for example, may feel they have little choice but to consent (Rajan, 2007).

Current animal and human trial regulations and procedures for the testing of new pharmaceutical products construct the response-abilities (capacities to respond and to take responsibility) and forms of their experimental subjects in different ways, most strongly marked in the distinction between humans and other species. For humans their capacity to respond is bisected into two distinct moments. Firstly, the situation whereby a patient-subject is recruited and engaged in the rational, reasoned, and language-based process of completing an informed consent form, who may, contraMol's (2008) citizen, be asked about his or her bodily well-being. Secondly, the moment when the patient's responses are measured as a part of the clinical trial. One focuses on the patient as a subject (including a concern for his or her welfare and comfort); the other, more on the patient as scientific research object (where his or her discomfort also marks a significant scientific finding). In contrast, in animal research both the animals' welfare as subjects and their responses as objects are measured in nonverbal ways during the experimental process. Laboratory animal welfare assessment procedures (Leach and Main, 2008) find ways of extending physiological observations of the animal to include a wider remit of animals' nonverbal responses to an experiment - for example, where it moves and how it moves, its appearance, its behaviour, its vocalisations.

This leads to the question of how far contemporary human clinical practices and protocols, and the experimental environments and relations they inscribe, allow patients the capacity for somatic expression and resistance and allow nurses to conduct 
experiments in which good care is seen as an essential component of good experimental practice. If we understand nursing as a bricoleur activity (Gobbi, 2005) that involves the development of somatic sensibilities, we might ask how far current experimental environments create opportunities for these sensibilities to be registered and responded to with care practices. This can be expressed as two emerging research questions. Firstly, what forms of response and interaction between experimental subjects and their wider environments can be seen to exceed contemporary ethical protocols and codes? Secondly, can we make spaces that allow experimental subjects and their experimenters to interact and respond to each other differently-in other words, spaces that are open to how intra-acting (Barad, 2007) bodies shape ethical sensibilities (see also Popke, 2009, page 84)? These questions could stimulate new directions in debates within bioethics and the social study of clinical trial practice. This has particular implications for how we work with those deemed incapable of giving informed consent, including babies, children, and those mentally incapacitated, who may be capable of articulating somatically signs of cooperation or dissent, distress, and discomfort. Calarco (2008, pages 131 -132) suggests that these groups occupy "a similar space of marginalization alongside animals". For these subjects, recognition of 'nonverbal' consent could play as important a role in ensuring ethical practice as critical anthropomorphism and animal welfare protocols do in animal experimentation.

An attention to somatic sensibilities also has something to offer for geographical research and practice. We argue that work in animal welfare, animal philosophy, and nursing research can offer further empirical and philosophical grounding for thinking through how emotion and affect can intervene in and condition the experimental process. Furthermore we suggest this work also offers ways of developing the kinds of skills and competencies needed to incorporate practices of care in geographical knowledge practices (Dewsbury and Naylor, 2002) and to develop research environments which enable both researcher and researched to articulate and respond.

Of course, equally there is a need to recognise the limitations of this approach. The recognition of somatic sensibilities in and of itself does not serve as a basis for generating the normative values that might inform the development of ethical procedures. Rather we suggest that an ethics derived from somatic sensibilities might be used to complement and extend existing ethical practices. To help guide such a development, we will conclude by identifying six emerging problems and areas for further research.

Firstly, to share suffering is arguably not the same as sharing the meanings and utilitarian ethical values that underpin choices to suffer, or not. In other words, somatic sensibilities begin from a place quite different from contemporary ethical norms that emerge from a utilitarian position (Singer, 2002) wherein the costs of animal or human suffering are weighed against the benefits of the research to (human) society as a whole. Therefore, installing a new ethical operation of somatic sensibilities will rub up against and conflict with previous norms. But this does not mean that this is an approach with no practical value. Sharing suffering can provide the basis for improved experimental design. For example, 'choice tests' usually used to assess living conditions may be adapted to also take account of the expressed need for analgesics, as was recently explored by research in farm-animal welfare (Danbury et al, 2000; see also Dawkins, 2006).

Secondly, the focus on the relationship between individual subjects (patient-nurse, lab animal-animal caretaker) leaves open the issue of how far this approach could contribute to a more generalised social awareness of, and ethical sensibilities towards, the many experimental subjects. As Popke (2009, page 84) suggests, perhaps here as in other nonrepresentational approaches to ethics, we are at risk of emphasising 
"individual encounters and experiences at the expense of a more extensive vision of collective responsibility", a shortcoming also of the 'choice-tests' used to ask what the animal wants in animal welfare science.

Thirdly, there is the inherent risk of instrumentalism, a problem already seen in some areas of animal welfare science. At the point of application, the ideals of the welfarist position and the process of observing and responding to animal suffering can be reduced to a list of tick-box procedures. Such processes go through the ethical motions, so to speak, without engaging in the kind of affective relations that might underpin a sustained ethical reflection and sensibility [a move also echoed by the training nurses receive in informed consent procedures; see Fisher (2006)]. If there were a normative commitment here, we would suggest it is found in a commitment to leaving space within experimental designs to allow a nurse or animal technician to respond to 'unfinished matters' (Hinchliffe, 2007, page 139) - to acknowledge the capacity for the subject to object, contest and resist, or comply with the experimental process (as Despret's rats were able to do). However, more work is needed to map out more fully the passage between a procedural commitment to the development of somatic sensibilities and a wider social debate about the implications these new relations and insights may have in public policies on human and animal research.

Fourthly, this highlights how the development of somatic sensibilities is limited by, and dependent on, our abilities to forge connections and understandings across species and cultural boundaries. It is notable that most of our discussions above focus on warm-blooded mammals. Arguments for the development of companionable relations (Haraway, 2008) and somatic sensibilities are arguably easier to envision with respect to charismatic animals (Lorimer, 2007) that are big-like-us (Hird, 2010) than it is to imagine empathising with mosquitoes (Beisel, 2010), microbes (Hird, 2009), or plants (Keller, 1984). This means we need to pay attention to the category animal in our discussions. As we noted above, the skills animal lab technicians develop in somatic sensibility are arguably species specific.

Fifthly, there are the specific geographies of the ethical encounters we described, which can play a key role in shaping the development of ethical relations (Greenhough, 2007; Jones, 2000; Whatmore, 1997). Our focus on laboratory spaces leaves open the question, as noted above, of how this context and species-specific form of relating might compare to other spaces of human-animal encounter. ${ }^{(15)}$ Recent work on human-nonhuman relations at other sites suggests that somatic sensibilities are also at work in the practices of field biology (Kohler, 2002), conservation (Hinchliffe et al, 2005), conservation science (Lorimer, 2008a), political debate (Bingham, 2006), and reindeer herding (Lorimer, 2006).

Finally, there also remains an implicit emphasis within the concept of somatic sensibility on proximity (being within touching distance) as central to the recognition of and engagement with somatic sensibilities. While this allows scope to explore how particular environments and modes of encounter create and constrain the development of somatic sensibilities, it fails to address the question of how these kinds of sensibilities might operate at a distance. Work on ethical consumption (Barnett et al, 2002) and notions of responsibility across distance (Clark, 2005; Clark et al, 2005) suggest a need to explore how far, if at all, somatic sensibilities might be engaged at a distance through mediated forms of encounter. This might include the kinds of empathy evoked through moving imagery, which is only just beginning to be explored within the geographical literature (J Lorimer, 2008b). Or the scientific practices that signal

(15) As scholars of science studies have noted, the scientific and geographical practices of humananimal relations are likely to change significantly as we move between laboratory and field (Burkhardt, 1999; Kohler, 2002; see also Dewsbury and Naylor, 2002). 
how an animal's stress is inscribed in matter and interpreted as poor quality meat on industrial meat-cutting lines (Roe, 2010). Emphasising proximate and immediate relations also obscures historical and temporal dimensions of animal research, and the underlying power relations they inscribe (Birke et al, 2007; Franklin, 2007). While developing somatic sensibility can arguably improve the welfare of experimental subjects, it is less helpful in engaging with the histories that have resulted in a medical industry dependent on the use of animal subjects as the assayers of our medical innovations. ${ }^{(16)}$ We need to recognise that "our affective encounters seldom take place in a space free from the exigencies of the real social relations and emotional investments that inflect our ethical orientations and influence our opportunities" (Popke, 2009, page 86). Further exploration of somatic sensibilities might take up the challenge of how those sense-abilities operate across different value systems, species, and spaces.

Acknowledgments. The authors would like to thank Jamie Lorimer, Gail Davies, and participants at the ESRC Science and Social Science of Animal Welfare workshop (UCL, 2008); the Nonrepresentational Geographies Session (AAG, 2008); and Nature and Supernatures Conference (Exeter, 2007) for useful feedback on earlier versions of this paper. Roe acknowledges the support of WelfareQuality $\circledR^{2}$ EU funded project FOOD-CT-2004-506508 and British Academy Grant SG-45237 for developing her understanding of animal welfare science.

\section{References}

Acampora R, 2006, Corporal Compassion (University of Pittsburgh Press, Pittsburgh, PA)

Andersen G, 2008, "Ethical preparedness and performance of gene therapy student co-ordinators" Nursing Ethics 15208 - 221

Anderson B, 2006, "Becoming and being hopeful: towards a theory of affect" Environment and Planning D: Society and Space $\mathbf{2 4} 733-752$

Anderson B, Harrison P, 2006, "Questioning affect emotion" Area 28333 - 335

Ashcroft R, 1999, "Equipoise, knowledge and ethics in clinical research and practice" Bioethics 13(3/4) $314-326$

Barad K, 2007 Meeting the Universe Halfway: Quantum Physics and the Entanglement of Matter and Meaning (Duke University Press, Durham, NC)

Barnett C, Cloke P, Clarke N, Malpass A, 2002, "Consuming ethics: articulating the subjects and spaces of ethical consumption" Antipode 37 23-45

Baumans V, 2005, "Science-based assessment of animal welfare: laboratory animals" Revue Scientifique et Technique de l'Office International des Epizooties 24 503-514

Beisel U, 2010, "Jumping hurdles with mosquitoes?" Environment and Planning D: Society and Space 28 46-49

Bennett J, 2001 The Enchantment of Modern Life (Princeton University Press, Woodstock, Oxon)

Bentham J, 1789 A Utilitarian View: The Principles of Morals and Legislation http://www.animalrights-library.com/texts-c/bentham01.htm

Bingham N, 2006, "Bees, butterflies, and bacteria: biotechnology and the politics of nonhuman friendship" Environment and Planning A 38483 - 498

Birke L, Arluke A, Michael M, 2007 The Sacrifice: How Scientific Experiments Transform Animals and People (Purdue University Press, Lafayette, IN)

Boden R, Epstein D, Latimer J, 2009, “Accounting for ethos or programmes for conduct? The brave new world of research ethics committees" The Sociological Review 57 727-749

Boo M J, Rennie A E, Buchanan-Smith H M, Hendricksen C F M, 2005, "The interplay between replacement, reduction and refinement: consideration where the Three R's interact" Animal Welfare $14327-332$

Boulton M, Parker M, 2007, "Informed consent in a changing environment" Social Science and Medicine $652187-2408$

Braun B, 2007, "Biopolitics and the molecularisation of life" Cultural Geographies 14 6-28

Buchanan-Smith H M, Rennie A E, Vitale A, Pollo S, Prescott M J, Morton D B, 2005,

"Harmonising the definition of refinement" Animal Welfare 14379 - 384

(16) This is a question currently being explored within the medical research literature [see Pound et al (2004) and associated responses]. 
Burkhardt R W, 1999, "Ethology, natural history, the life sciences, and the problem of place" Journal of the History of Biology 32 489-508

Butler R, Parr H, 1999 Mind and Body Spaces: Geographies of Illness, Impairment and Disability (Routledge, London)

Calarco M, 2008 Zoographies: The Question of the Animal from Heidegger to Derrida (Columbia University Press, New York)

Clark N, 2005, "Disaster and generosity" Geographical Journal 171384 -386

Clark N, Greenhough B, Jazeel T, 2005, "Reply: when response becomes responsibility" Geographical Journal $172248-250$

ClinicalTrials.gov, 2007, "Understanding clinical trials", http://clinicaltrials.gov/ct2/info/ understand\#Q19

Coghlan A, 2006, "Animal welfare: seeing things from their perspective" New Scientist (2570) 6-7

Danbury T C, Weeks C A, Waterman-Pearson A E, Kestin S C, Chambers J P, 2000, "Self-selection of the analgesic drug carprofen by lame broiler chickens" The Veterinary Record 146 307-311

Davies G, 2006, "The sacred and the profane: biotechnology, rationality, and public debate" Environment and Planning A $38423-443$

Dawkins M S, 2006, "Through animal eyes: what behaviour tells us" Applied Animal Behaviour Science $1004-10$

Dawson A, 2003, "Informed consent: should we insist upon it?" New Review of Bioethics 1 59-71

Despret V, 2004, "The body we care for: figures of anthropo-zoo-genesis" Body and Society $10(2 / 3) 111-134$

Dewsbury J-D, 2000, "Performativity and the event: enacting a philosophy of difference" Environment and Planning D: Society and Space 18473 - 496

Dewsbury J-D, 2003, "Witnessing space: 'knowledge without contemplation" "Environment and Planning A 351907 - 1932

Dewsbury J-D, Naylor S, 2002, "Practising geographical knowledge: fields, bodies and dissemination" Area $34253-260$

Dyck I, Kontosb P, Angusc J, McKeeverc P, 2005, “The home as a site for long-term care: meanings and management of bodies and spaces" Health and Place 11 173-185

Dyer S, 2004, "Rationalising public participation in the health service: the case of research ethics committees" Health and Place $10339-348$

Dyer S, Demeritt D, 2009, "Un-ethical review? Why it is wrong to apply the medical model of research governance to human geography" Progress in Human Geography 33 46-64

Edwards S J L, 2006, "Restricted treatments, inducements and research participation" Bioethics $2077-91$

Ehni H, Wiesing U, 2008, "International ethical regulations on placebo-use in clinical trials: a comparative analysis" Bioethics $2264-74$

European Union Clinical Trials Directive, 2001, European Parliament

FAWC, 2007, "Report on stockmanship and farm animal welfare", Farm Animal Welfare Council, http://www.fawc.org.uk/reports.htm

Fenwick N P, Fraser D, 2005, "The Three R's in the pharmaceutical industry: perspectives of scientists and regulators" Animal Welfare $14367-377$

Fisher J, 2006, "Co-ordinating 'ethical' clinical trials: the role of research coordinators in the contract research industry" Sociology of Health and Illness 28 678-694

Franklin S, 2007 Dolly Mixtures: The Remaking of Genealogy (Duke University Press, Durham, NC)

Gobbi M, 2005, "Nursing practice as bricoleur activity: a concept explored" Nursing Inquiry $12117-125$

Grandin T, 2006 Thinking in Pictures: My Life with Autism (Vintage, New York)

Greenhough B, 2007, "Situated knowledges and the spaces of consent" Geoforum 36 1140-1151

Grosz E, 1995, Space, Time and Perversion: Essays on the Politics of Body (Routledge, London)

Hall E, 2000, "'Blood, brain and bones': taking the body seriously in the geography of health and impairment" Area 32 21 - 29

Haraway D, 2008 When Species Meet (University of Minnesota Press, Minneapolis, MN)

Harlow H, 1964, "An experimentalist views the emotion", in Expressions of the Emotion in Man Ed. P Knapp (International University Press, New York) pp 254-261

Harrison P, 2007, “'How shall I say it ... ?' Relating the nonrelational” Environment and Planning A $39590-608$

Hinchliffe S, 2007 Geographies of Nature: Societies, Environments, Ecologies (Sage, London)

Hinchliffe S, Bingham N, 2008, "Securing life: the emerging practices of biosecurity" Environment and Planning A $401534-1551$ 
Hinchliffe S, Kearnes M B, Degen M, Whatmore S, 2005, "Urban wild things: a cosmopolitical experiment" Environment and Planning D: Society and Space $23643-658$

Hird M, 2009, The Origins of Sociable Life: Evolution after Science Studies (Palgrave Macmillan, Basingstoke, Hants)

Hird M J, 2010, "Meeting with the microcosmos" Environment and Planning D: Society and Space $2836-39$

Hoeyer K, 2003, “'Science is really needed - that's all I know': informed consent and the non-verbal practices of collecting blood for genetic research in northern Sweden" New Genetics and Society $22229-244$

Holloway L, 2005, "Aesthetics, genetics, and evaluating animal bodies: locating and displacing cattle on show and in figures" Environment and Planning D: Society and Space 23 883-902

Jones O, 2000, “(Un)ethical geographies of human - non-human relations: encounters, collectives and spaces", in Animal Spaces, Beastly Places Eds C Philo, C Wilbert (Routledge, London) pp $268-291$

Katz J, 2000 How Emotions Work (University of Chicago Press, Chicago, IL)

Keller E F, 1984 A Feeling for the Organism: The Life and Work of Barbara McClintock (Chicago University Press, Chicago, IL)

Kohler R E, 2002, "Place and practice in field biology" History of Science 40 189-210

Latour B 1993 We Have Never Been Modern translated by C Porter (Harvard University Press, Cambridge, MA)

Lawler J, 1991 Behind the Scenes: Nursing, Somology, and the Problem of the Body (Churchill Livingstone, Edinburgh)

Lea J, 2009, "Becoming skilled: the cultural and corporeal geographies of teaching and learning Thai Yoga massage" Geoforum $40465-474$

Leach M, Main D, 2008, "An assessment of laboratory mouse welfare in UK animal units" Animal Welfare 17171 - 187

Longhurst R, 1997, “(Dis)embodied geographies” Progress in Human Geography 21 486-501

Lorimer H, 2005, "Cultural geography: the busyness of being 'more-than-representational'" Progress in Human Geography $2983-94$

Lorimer H, 2006, "Herding memories of humans and animals" Environment and Planning D: Society and Space $\mathbf{2 4} 497-518$

Lorimer J, 2007, "Nonhuman charisma” Environment and Planning D: Society and Space 25911 - 932

Lorimer J, 2008a, "Counting corncrakes: the affective science of the UK corncrake census" Social Studies of Science $\mathbf{3 8} 377-405$

Lorimer J, 2008b, "Witnessing affect: video methodologies for more-than-human geographies", presented at the 2008 AAG Annual Meeting, Boston, MA, contact J Lorimer, Department of Geography, Kings College London

McCormack D, 2003, "An event of geographical ethics in spaces of affect" Transactions of the Institute of British Geographers, New Series 28488 - 507

Mol A, 2008 The Logic of Care: Health and the Problem of Patient Choice (Routledge, London)

Morton D B, Burghardt G M, Smith J A, 1990, "Section III: Critical anthropomorphism, animal suffering, and the ecological context" Hastings Center Report Special Supplement, 13 - 19

MRC, 1998, "Guidelines for good practice in clinical trials", http://www.mrc.ac.uk/Utilities/ Documentrecord/index.htm?d=MRC002416

MRC, 2005, "Medical Research Council position statement on research regulation and ethics", http://www.mrc.ac.uk/Utilities/Documentrecord/index.htm?d=MRC002462

Mueller M R, 1997, "Science versus care: physicians, nurses and the dilemma of clinical research", in The Sociology of Medical Science and Technology Ed. M A Elston (Blackwell, Oxford) pp 57-78

Nast H J, Pile S, 1998 Places Through the Body (Routledge, London)

O'Hanlon L, 2001, "Do unhappy mice give bad information?" BioMedNet News and Comment 9 August

Paterson M, 2005, "Affecting touch: towards a felt phenomenology of therapeutic touch", in Emotional Geographies Eds J Davidson, L Bondi, M Smith (Ashgate, Aldershot, Hants) pp $161-176$

Parr H, 2002, "Medical geography: diagnosing the body in medical and health geography, 1999 - 2000" Progress in Human Geography 26 240 - 251

Petryna A, 2006, "Globalizing human subjects research", in Global Pharmaceuticals: Ethics, Markets, Practices Eds A Petryna, A Lakoff, A Kleinman (Duke University Press, Durham, NC) pp $33-60$ 
Popke J, 2009, "Geography and ethics: non-representational encounters, collective responsibility and economic difference" Progress in Human Geography 33 81-90

Pound P, Ebrahim S, Sandercock P, Bracken M B, Roberts I, 2004, "Where is the evidence that animal research benefits humans?" British Medical Journal 328514 - 517

Proctor J D, Smith D M, 1999 Geography and Ethics: Journeys in a Moral Terrain (Routledge, London)

Rajan K, 2007, "Experimental values: Indian clinical trials and surplus health" New Left Review $45 \mathrm{http} / / /$ newleftreview.org/?view $=2670$

RCN, 2006, "Informed consent in health and social care research", Royal College of Nursing, http://www.ukcrn.org.uk/index/training/courses/other-courses/VIC/VIC_resources/ mainColumnParagraphs/04/document/\%28A2\%29\%20Informed \%20consent\%20in\%20health $\% 20$ and \%20social\%20care\%20research\%20RCN.pdf

RCN, 2008, "Competency framework for clinical trial nurses", Royal College of Nursing, http://www.rcn.org.uk/__data/assets/pdf_file/0019/201466/Competency_Framework_v1_dec08.pdf

Roe E, 2010, "Ethics and the nonhuman. The matterings of animal sentience in the meat industry", in Taking-place: Non-representational Geographies and Philosophy Eds B Anderson, P Harrison (Ashgate, London) pp $261-280$

Rudge T, 2009, "Beyond caring? Discounting the differently known body", in The Unknown/Known Body Eds J Latimer, M Schillmeier, Sociological Review Monographs Remembering Elites Series (Wiley-Blackwell, Bognor Regis, West Sussex) pp 235-250

Russell W M S, Burch R L, 1959 The Principles of Humane Experimental Technique (Methuen, London)

Singer P, 2002 [1975] Animal Liberation (HarperCollins, New York)

Stengers I, 1997 Power and Invention (University of Minnesota Press, Minneapolis, MN)

The Medicines for Human Use (Clinical Trials) Regulations, 2004, Government of United Kingdom

Thrift N, 2003, "Summoning life", in Envisioning Human Geographies Eds P Cloke, P Crang, M Goodwin (Arnold, London) pp $81-103$

Thrift N, 2008 Non-representational Theory: Space, Politics, Affect (Routledge, London)

van Ness P H, 2001, "The concept of risk in biomedical research involving human subjects" Bioethics $15364-370$

Vorstenbosch J M C, 2005, “The ethics of the Three R's principle: a reconsideration" Animal Welfare $14339-345$

Wemelsfelder F, 2007, "How animals communicate quality of life: the qualitative assessment of animal behaviour" Animal Welfare 16(8) 25-31

Whatmore S, 1997, "Dissecting the autonomous self: hybrid cartographies for a relational ethics" Environment and Planning D: Society and Space 1537 - 53

Whatmore S, 2002 Hybrid Geographies: Natures, Cultures and Spaces (Sage, London)

Wolfe, C, 2003, "Introduction", in Zoontologies Ed. C Wolfe (University of Minnesota Press, Minneapolis, MN) pp ix - xxiii 
Conditions of use. This article may be downloaded from the E\&P website for personal research by members of subscribing organisations. This PDF may not be placed on any website (or other online distribution system) without permission of the publisher. 